\title{
Histologic variants of acinar prostate carcinomas: Clinicopathologic importance
}

\author{
Harmanjot Singh ${ }^{1}$, Ziad M. El-Zaatari' ${ }^{1}$, Jae Y. Ro ${ }^{1,2}$
}

Cite this article: Singh $\mathrm{H}$, El-Zaatari ZM, Ro JY: Histologic variants of acinar prostate carcinomas: clinicopathologic importance. Ann Urol Oncol 2020; 3(1): 36-46. https://doi.org/10.32948/ auo.2020.12.19

\begin{abstract}
Acinar carcinoma comprises more than $90 \%$ of prostatic adenocarcinomas and is characterized by a small gland proliferation with an infiltrative growth pattern. The numerous, variably-defined histological variants of prostatic adenocarcinoma can prove to be diagnostic challenges and show prognostic differences when compared to the usual acinar carcinoma, thus emphasizing the importance in accurate recognition.

Variants of acinar prostatic adenocarcinoma include the atrophic, pseudohyperplastic, microcystic, foamy gland, mucinous (colloid), signet ring-like cell, pleomorphic giant cell, and sarcomatoid variants. The atrophic, pseudohyperplastic, microcystic, and foamy gland variants can be challenging to diagnose due to their deceptively benign appearance. While the atrophic, pseudohyperplastic, microcystic, and foamy gland variants usually present as low-grade malignancies (Gleason score 6-7), the mucinous (colloid), signet ring-like cell, pleomorphic giant cell, and sarcomatoid variants often present as high-grade malignancies (Gleason score $>7$ ) and are usually associated with a worse prognosis.

Small cell carcinoma is not considered as a variant of acinar carcinoma, is classified under neuroendocrine tumors, and is recommended not to be assigned a Gleason score. Small cell carcinoma is often preceded by a diagnosis of acinar adenocarcinoma, rarely presents as a de novo tumor, and, as in other organs systems has an aggressive clinical course.

In this review article, we discuss variants of prostatic acinar carcinomas and briefly discuss small cell carcinoma. Awareness of variants of acinar prostate carcinoma and their clinicopathologic features is essential to rendering an accurate diagnosis and clinical management of patients with these tumors.
\end{abstract}

Key words Prostate, acinar carcinoma, histologic variants, clinicopathologic importance

1. Department of Pathology and Genomic Medicine, Houston Methodist Hospital. Houston, Texas, 77030, USA.

2. Weill Medical College of Cornell University (WCMC), New York, 10065, USA.

Correspondence: Jae Y. Ro (Department of Pathology and Genomic Medicine, Houston Methodist Hospital, 6565 Fannin Street, Houston, Texas, 77030 USA; Email: jaero@houstonmethodist.org). 


\section{Introduction}

Prostate cancer is the most common cancer and the second most common cause of cancer death in men in USA [1]. Most prostate cancers are adenocarcinomas categorized as acinar adenocarcinoma or ductal adenocarcinoma. The incidence of adenocarcinoma is variable among races in different countries, with the highest reported incidence in North America, Australia, and Scandinavian countries [2]. Acinar carcinoma comprises more than $90 \%$ of prostatic adenocarcinomas and is characterized by a small gland proliferation with an infiltrative growth pattern. When assessing for the possibility of acinar adenocarcinoma of the prostate in biopsy or transurethral resection of prostate (TURP) specimens, a simple triad of the "three toos": too small glands, too crowded glands with back- to- back arrangement, and too clear glands is useful in screening and identifying carcinoma (Figure 1A). When any of the "three toos" is seen, one must consider the possibility of prostatic adenocarcinoma. To confirm the diagnosis of carcinoma, an additional three important diagnostic features should be present, which are: (1) nuclear enlargement, (2) prominent nucleoli and, (3) lack of basal cells (Figure 1B) [2].

Features that can aid in the diagnosis of prostate cancer include the presence of intraluminal crystalloids, pink amorphous secretions, and intraluminal acid mucin, although these features are not considered pathognomonic of acinar adenocarcinoma as they may be seen in numerous carcinoma mimickers. Common adenocarcinoma mimickers include atypical adenomatous hyperplasia (adenosis), sclerosing adenosis, basal cell hyperplasia, and clear cell cribriform hyperplasia [2]. Features including collagenous micronodules (mucinous fibroplasia), glomerulation, circumferential perineural invasion and glands involving fat are pathognomonic for the diagnosis of prostate cancer.

The most important prognostic and predictive factors for prostate cancer include TNM stage, Gleason grade, and serum PSA level. In this review article, we review the histologic variants of acinar prostate carcinomas, their morphologic characteristics, and clinicopathologic features. The WHO classification of epithelial prostate tumors included acinar carcinoma in addition to morphologic variants of acinar carcinoma and other epithelial prostate tumors (Table 1) [3]. Although small cell carcinoma is categorized as a neuroendocrine tumor in the WHO classification, we briefly touch on small cell carcinoma in this article because this tumor is often preceded by a diagnosis of acinar adenocarcinoma (Table 2).

\section{Atrophic variant}

Atrophic variant adenocarcinoma is characterized by malignant glands with atrophic features. It is characterized by cytoplasmic volume loss similar to that seen in benign atrophy [4-7]. By comparison, the usual variant of acinar adenocarcinoma demonstrates a moderate amount of cytoplasm. The atrophic variant can be seen following radiation or androgen deprivation therapy, or in a sporadic setting [4-7]. The glands are oval to round and typically small with virtually all cases showing atrophic malignant glands intermixed with the malignant glands of the usual acinar variant of adenocarcinoma. No cases of pure atrophic pattern adenocarcinoma have been reported to date [5]. An infiltrative arrangement of glands displaying loss of cytoplasmic volume, macronucleoli, and nucleomegaly are seen in Figures 2A and 2B. The incidence of sporadic atrophic variant of adenocarcinoma is approximately $2 \%$ in needle core biopsy specimens [5] and approximately $16 \%$ in radical prostatectomy specimens, with few reported cases in TURP specimens [4].

The proportion of the atrophic tumor comprised of glands with atrophic features is variable, averaging $16-25 \%$ of the total adenocarcinoma showing glands with atrophic features $[5,6]$. The reported range is broad, $10-90 \%$ in needle biopsy cases [5] and $1-70 \%$ in radical prostatectomy cases $[5,6]$. Thus, pure atrophic pattern of adenocarcinoma should not be diagnosed in needle biopsy cases, as recognition and discrimination from benign atrophy can serve as a diagnostic dilemma.

When considering the differential diagnosis, it is imperative to distinguish between the atrophic pattern of adenocarcinoma and benign atrophy. The most reliable features supporting a diagnosis of atrophic variant of adenocarcinoma over benign atrophy remain to be infiltrative growth pattern, nuclear atypia, and the diffuse absence of basal cells [4-6]. Additional features include the presence of intraluminal pink secretions, intraluminal wispy blue mucin, and intraluminal crystalloids; however, these findings have been shown to be detected in only a minority of atrophic variant adenocarcinoma cases [3], limiting their diagnostic utility.

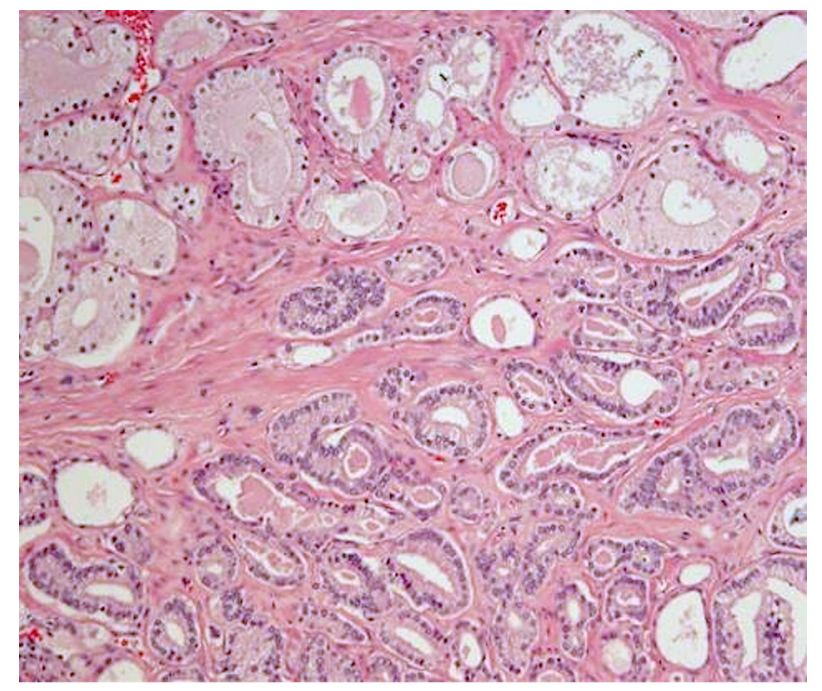

A

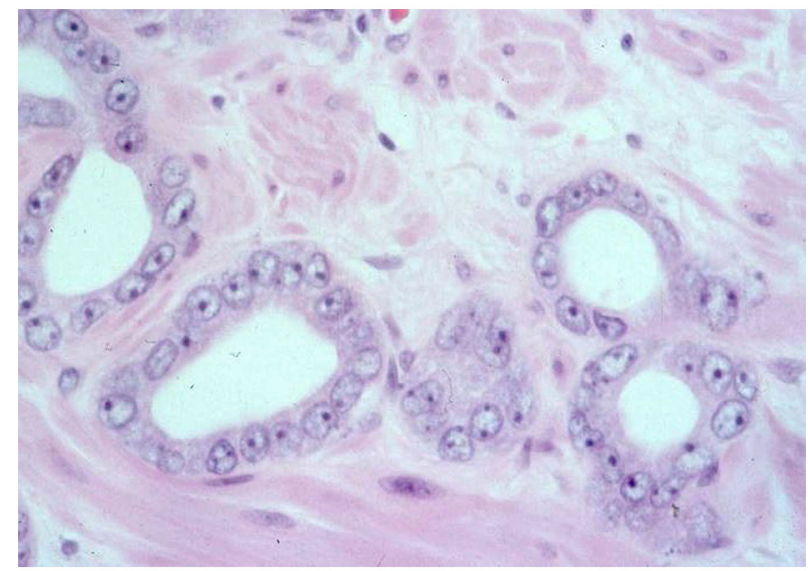

B

Figure 1. The "three "toos" of acinar adenocarcinoma. A: The "three "toos" (too small glands, too crowded glands with back- to- back arrangement, and too clear glands) as seen in this figure are useful in screening and identifying carcinoma. (Hematoxylin and eosin stain, 40X magnification). B: To confirm the usual variant of acinar adenocarcinoma, a diagnostic triad is required: enlarged nuclei, prominent nucleoli, and lack of basal cells. (Hematoxylin and eosin stain, 400X magnification). 
Table 1. World Health Organization classification of Epithelial Tumor of Prostate.

\begin{tabular}{ll} 
Glandular neoplasms & ICD-0* \\
\hline
\end{tabular}

Acinar adenocarcinoma

Atrophic

Pseudohyperplastic

Microcystic

Foamy gland

Mucinous (colloid)

Signet ring-like cell

Pleomorphic giant cell

Sarcomatoid

Prostatic intraepithelial neoplasia, high grade

Intraductal carcinoma

Ductal adenocarcinoma

Cribriform

Papillary

Solid

Urothelial Carcinoma

Squamous neoplasms

Adenosquamous carcinoma

* International Classification of Disease for Oncology; Modified from WHO Classification of Tumours of the Urinary System and Male Genital Organs $4^{\text {th }}$ edition [3].

Perineural invasion may also be seen. A potential pitfall in the differential diagnosis of atrophic pattern of adenocarcinoma versus benign atrophy includes the potential for immunophenotypic overlap. Up to $6-23 \%$ of cases of benign atrophy are negative for basal cell markers [8-13]. AMACR can show overexpression in up to $4 \%$ of cases of benign atrophy $[14,15]$ and $10-79 \%$ of cases of partial atrophy $[8,9,12,16]$. These findings show that benign atrophy may show a malignant phenotype consisting of AMACR overexpression and basal cell loss.

Other diagnostic challenges are posed by atrophic pattern of acinar carcinoma. Atrophic pattern of adenocarcinoma may resemble the microcystic variant of acinar adenocarcinoma, which may also have lining tumor cells showing loss of cytoplasmic volume resembling atrophic features [5, 6, 17]. Identification of nuclear atypia within malignant glands in the atrophic variant can be challenging due to nuclear compression. AMACR expression has also been found to be diminished in the atrophic variant compared to cases of usual acinar adenocarcinoma, with positivity rates of $70 \%$ and $90 \%$ respectively [14]. Still, similar to the usual acinar variant of adenocarcinoma, there is complete loss of basal cells in all atrophic pattern adenocarcinoma glands as seen by immunohistochemistry using antibodies directed against highmolecular-weight cytokeratins and p63 [6].

Atrophic pattern adenocarcinoma is predominantly a Gleason pattern 3 carcinoma but may show Gleason pattern 4 in the usual acinar component in up to $13 \%$ of cases [6]. The proliferation index of atrophic pattern adenocarcinoma (4\%), as determined by Ki-67 immunolabeling, is similar to that of the usual acinar adenocarcinoma (5\%) with rare identification of mitoses $[6,16]$. The presence of atrophic features in adenocarcinoma is unlikely to be of prognostic significance as adenocarcinomas with and without atrophic change do not differ in Gleason grade or pathologic stage 
Table 2. World Health Organization classification of Neuroendocrine Tumors of the Prostate.

\begin{tabular}{lc}
\hline Tumors type & ICD-0* \\
\hline $\begin{array}{l}\text { Adenocarcinoma } \\
\text { with neuroendocrine } \\
\text { differentiation }\end{array}$ & $8574 / 3$ \\
$\begin{array}{l}\text { Well-differentiated } \\
\text { neuroendocrine tumor }\end{array}$ & $8240 / 3$ \\
$\begin{array}{l}\text { Small cell neuroendocrine } \\
\text { carcinoma }\end{array}$ & $8041 / 3$ \\
$\begin{array}{l}\text { Large cell neuroendocrine } \\
\text { carcinoma }\end{array}$ & $8013 / 3$ \\
\hline
\end{tabular}

* International Classification of Disease for Oncology; Modified from WHO Classification of Tumours of the Urinary System and Male Genital Organs $4^{\text {th }}$ edition [3].

\section{$[6,18]$.}

\section{Pseudohyperplastic variant}

The pseudohyperplastic variant can simulate the appearance of usual epithelial hyperplasia often seen in benign prostatic hyperplasia and accounts for a large percentage of needle biopsy cases misdiagnosed as benign prostate $[19,20]$. The incidence in needle biopsy cases is $2 \%$ [21], $11 \%$ in radical prostatectomy cases [22], and 3\% of TURP cases [21]. This variant demonstrates branching, papillary infoldings, luminal undulations, and cystic dilatation with a predominantly nodular configuration (see Figure 3A). A minority of cases may show an infiltrative component [21].
The tumor may be present in the transition and/or peripheral zone. In radical prostatectomy cases, there is almost always an associated usual small acinar adenocarcinoma component, although in needle core biopsy cases, up to $90 \%$ of the adenocarcinoma may be pseudohyperplastic [19]. The nuclei are rounded, without stratification, and typically show prominent nucleoli. Nuclear atypia may be minimal in some cases, particularly in cases with foamy cytoplasmic features $[16,20]$. Intraluminal crystalloids, pink amorphous secretions, and wispy blue mucin are seen in a minority of cases [16, 19, 21].

The differential diagnosis includes crowded benign glands, usual glandular hyperplasia of the prostate, and ductal adenocarcinoma. Findings useful in establishing a diagnosis of malignancy include
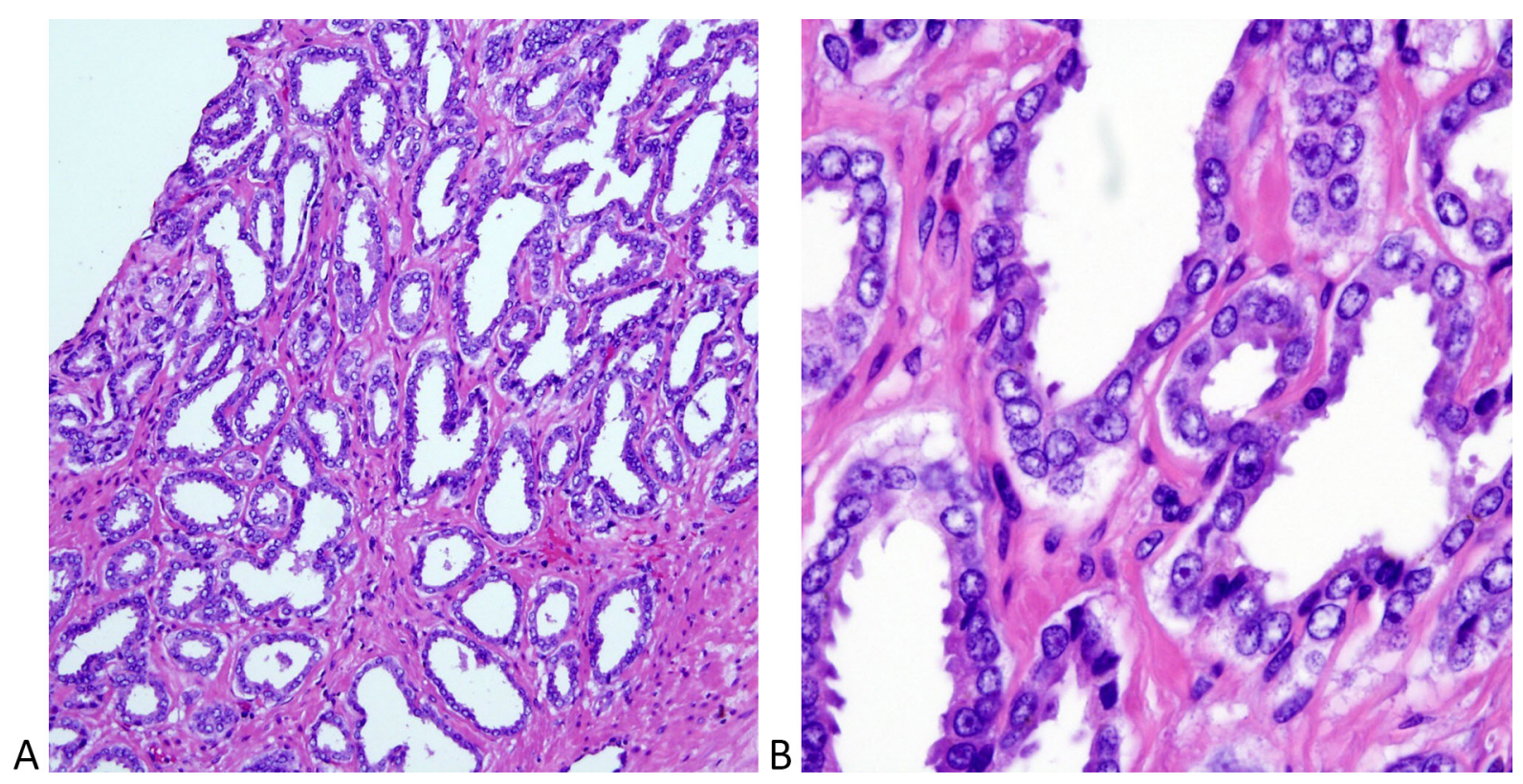

Figure 2. Atrophic variant of acinar adenocarcinoma. A: Atrophic variant of acinar adenocarcinoma consisting of crowded, round to irregular and angulated glands with scant cytoplasm, mimicking benign atrophy. (Hematoxylin and eosin stain, 40X magnification); B: Higher magnification image showing the cytologic features observed in this example of atrophic variant of prostatic adenocarcinoma including enlarged nuclei, prominent nucleoli, and lack of basal cells. Note scanty cytoplasm different from classic acinar carcinoma. (Hematoxylin and eosin stain, 200X magnification). 
Table 3. Histologic features of Variants of Usual Acinar Adenocarcinoma of the Prostate.

\begin{tabular}{|c|c|c|c|}
\hline Tumors type & Pattern & Gleason score & Differential diagnosis \\
\hline Atrophic & Atrophic with loss of cytoplasm & $6(3+3)$ & Atrophy \\
\hline Pseudohyperplastic & $\begin{array}{l}\text { Cystically dilated medium to large-caliber } \\
\text { glands that can mimic benign hyperplasia with } \\
\text { papillary infoldings and luminal undulations; } \\
\text { nuclei round with prominent nucleoli and } \\
\text { without pseudostratification }\end{array}$ & $6(3+3)$ & $\begin{array}{l}\text { Benign crowded glands } \\
\text { Benign glandular hyperplasia } \\
\text { Ductal adenocarcinoma }\end{array}$ \\
\hline Microcystic & $\begin{array}{l}\text { Cystically dilated medium-caliber glands } \\
\text { with round profiles and flat luminal cell lining } \\
\text { mimicking benign cystic atrophy }\end{array}$ & $\begin{array}{l}6(3+3) \text { in } \\
\text { majority with } \\
\text { approximately } \\
36 \% \text { showing } \\
\text { Gleason score } \\
7\end{array}$ & $\begin{array}{l}\text { Benign cystic atrophy of transition } \\
\text { zone } \\
\text { Cystic hyperplasia of transition zone }\end{array}$ \\
\hline Foamy & $\begin{array}{l}\text { Tumor cells with foamy/xanthomatous } \\
\text { cytoplasm and small, pyknotic appearing } \\
\text { nuclei, often admixed with non-foamy gland } \\
\text { carcinoma }\end{array}$ & $\begin{array}{l}7 \text { (most } \\
\text { common 60\%), } \\
6(32 \%), 9-10 \\
(5 \%), 8(3 \%)\end{array}$ & $\begin{array}{l}\text { Cowper's glands } \\
\text { Histiocytes }\end{array}$ \\
\hline Mucinous (Colloid) & $\begin{array}{l}\text { Individual glands, fused glands, cribriform } \\
\text { nests floating in extracellular mucin pools or } \\
\text { lakes (at least } 25 \% \text { for mucinous carcinoma). } \\
\text { Mucinous carcinoma cannot be made on } \\
\text { biopsies. }\end{array}$ & 7 or 8 & Metastasis \\
\hline Signet ring-like cell & $\begin{array}{l}\text { Tumor cells with empty vacuoles lacking } \\
\text { intracellular mucin; at least } 25 \% \text { of tumor } \\
\text { cells composed of signet ring-like cells }\end{array}$ & $9-10$ & Metastasis \\
\hline $\begin{array}{l}\text { Pleomorphic Giant } \\
\text { Cell }\end{array}$ & $\begin{array}{l}\text { Giant, bizarre, anaplastic tumor cells with } \\
\text { pleomorphic nuclei with no spindle cell } \\
\text { component }\end{array}$ & $9-10$ & $\begin{array}{l}\text { Sarcomatoid carcinoma with marked } \\
\text { nuclear pleomorphism } \\
\text { Tumors with osteoclast-type or } \\
\text { trophoblastic giant cells } \\
\text { Metastasis }\end{array}$ \\
\hline Sarcomatoid & $\begin{array}{l}\text { Biphasic neoplasm with tumor cells showing } \\
\text { epithelial and sarcomatoid differentiation; } \\
\text { sometimes display mixture of sarcomatoid } \\
\text { component and typical adenocarcinoma }\end{array}$ & $\begin{array}{l}\text { Epithelial } \\
\text { component } \\
\text { usually } \\
\text { showing high } \\
\text { Gleason score } \\
(9-10)\end{array}$ & Metastasis (urothelial or GI tract) \\
\hline $\begin{array}{l}\text { Small cell } \\
\text { carcinoma }\end{array}$ & $\begin{array}{l}\text { Small to medium sized, round to oval cells } \\
\text { with minimal cytoplasm, finely dispersed } \\
\text { nuclear chromatin, no distinct nucleoli, } \\
\text { numerous apoptotic cells and high mitotic rate }\end{array}$ & Not assigned & $\begin{array}{l}\text { Large cell neuroendocrine carcinoma } \\
\text { (rare) } \\
\text { Metastasis }\end{array}$ \\
\hline
\end{tabular}

glandular crowding, nucleomegaly, prominent macronucleoli, and transition to usual acinar adenocarcinoma. A search for adjacent typical acinar adenocarcinoma is essential. As seen with cases of atrophic variant adenocarcinoma, pure pseudohyperplastic adenocarcinoma should not be diagnosed in needle biopsy cases and one should maintain a low threshold for performance of immunohistochemistry in such cases concerning for this variant. AMACR expression is seen in $70-83 \%$ of cases [23] without the presence of basal cells in concerning glands by immunostaining (Figure 3B). While detected in only a minority of cases, perineural invasion by pseudohyperplastic glands, when present, can aid in the diagnosis. The papillary growth pattern of pseudohyperplastic adenocarcinoma may be mistaken for the papillae of ductal adenocarcinoma of the prostate. However, the neoplastic epithelial lining is typically pseudostratified with elongated nuclei in ductal adenocarcinoma [24], whereas the lining cells of pseudohyperplastic adenocarcinoma papillae do not show stratification and have rounded, basally located nuclei.

Pseudohyperplastic adenocarcinomas are Gleason pattern 3 tumors within the prostate [25] and may metastasize [21]. The prognosis of patients with pseudohyperplastic adenocarcinoma is uncertain, but likely favorable. There is no significant difference in prognosis by pathologic stage for cases with and without hyperplastic features [21].

\section{Microcystic variant}

Microcystic acinar adenocarcinoma exhibits intermediate-sized glands with cystic dilatation. On average, the glands are 10 times the size of usual acinar adenocarcinoma and show rounded 

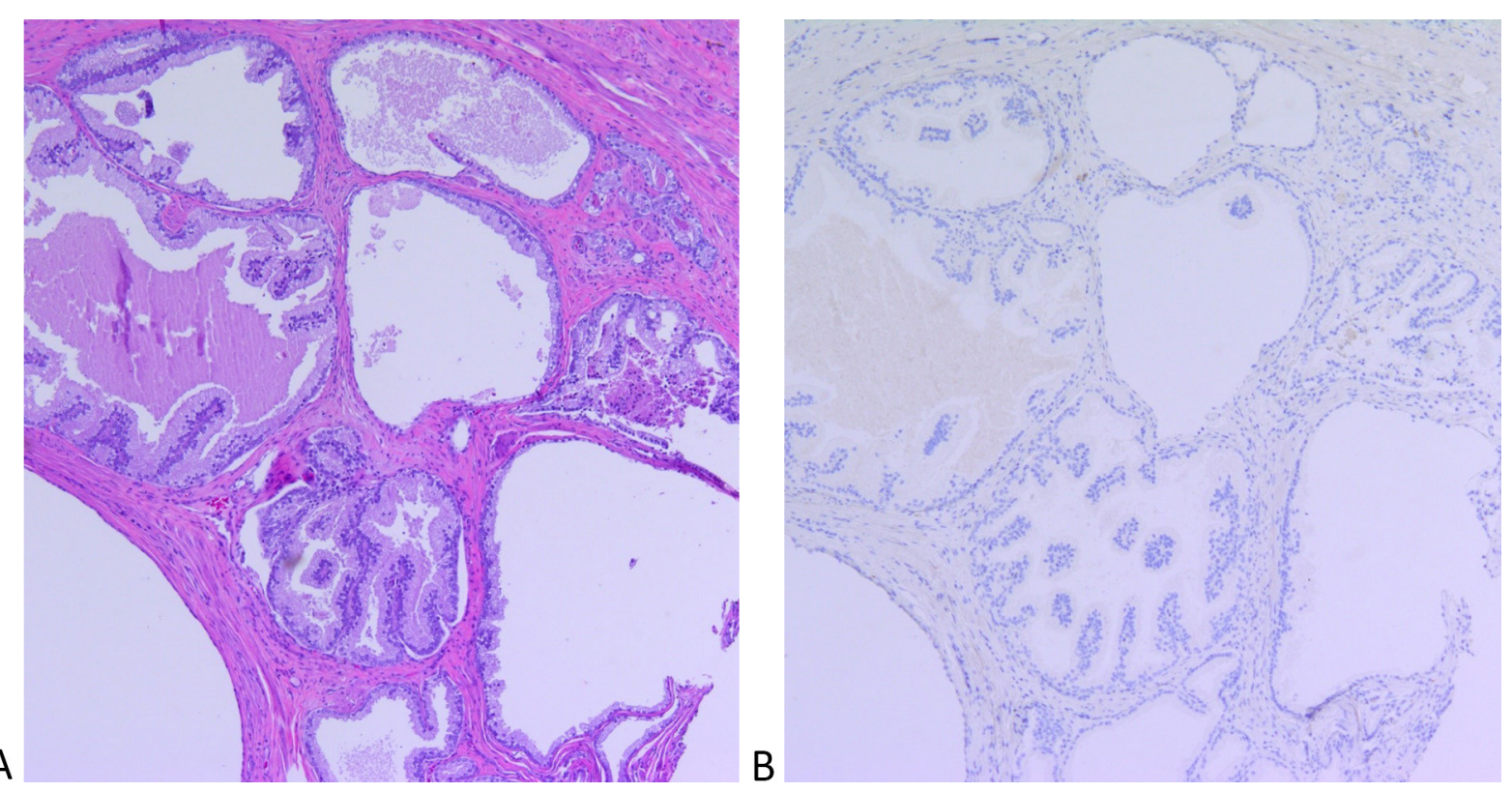

Figure 3. Pseudohyperplastic variant of acinar adenocarcinoma. A: Pseudohyperplastic variant of acinar adenocarcinoma composed of medium to large-sized glands showing dilatation and papillary infoldings with a deceptively benign appearance. A focus usual acinar adenocarcinoma (arrow) is seen adjacent to the malignant glands of pseudohyperplastic variant adenocarcinoma. (Hematoxylin and eosin stain, 40X magnification); B: An immunohistochemical for p63 demonstrates a complete lack of staining for basal cells in usual acinar carcinoma (arrow) and pseudohyperplastic carcinoma focus (open arrow) indicating these glands to be malignant in nature. (Hematoxylin and eosin stain, 40X magnification).

profiles and a flat luminal cell lining, simulating benign cystic atrophy of the prostate (Figure 4A). Up to $11 \%$ of usual acinar adenocarcinomas exhibit microcystic foci in radical prostatectomy cases [8]. AMACR expression is seen in almost all cases (96\%), with the dilated glands lacking basal cells (Figure 4B) [16, 17].

The differential diagnosis includes cystic hyperplasia and cystic atrophy of the transition zone [26]. Findings useful in establishing a diagnosis of malignancy within microcystic glands include nuclear atypia, AMACR overexpression, lack of basal cells, and adjacent small acinar adenocarcinoma. Ductal adenocarcinomas of the prostate may also show cystic dilatation of the malignant glands, which can occasionally be seen microscopically and macroscopically $[27,28]$. However, they differ from microcystic acinar adenocarcinomas in that the cysts are typically large (5$10 \mathrm{~mm}$ ) and show intracystic papillae [16, 27]. In contrast, the malignant glands of microcystic acinar adenocarcinoma range from 0.4 to $0.9 \mathrm{~mm}$, and typically have a flat malignant lining layer [17].

The assigned Gleason pattern is 3 for microcystic adenocarcinoma. While this is largely a low-grade adenocarcinoma, up to $36 \%$ of radical prostatectomy cases harbor Gleason pattern 4 elsewhere within the prostate [17], demonstrating that presence of only microcystic adenocarcinoma in a prostate needle biopsy specimen may indicate high-grade pattern 4 in the whole gland that was not sampled at the time of the biopsy. Uncommonly, the microcystic adenocarcinoma glands have been reported to invade into periprostatic adipose tissue [7], leading to a higher $\mathrm{pT}$ tumor classification. Microcystic acinar adenocarcinoma exhibits intermediate-sized glands with cystic dilatation. On average, the glands are 10 times the size of usual acinar adenocarcinoma and show rounded profiles and a flat luminal cell lining, simulating benign cystic atrophy of the prostate (Figure 4A). Up to $11 \%$ of usual acinar adenocarcinomas exhibit microcystic foci in radical prostatectomy cases [8]. AMACR expression is seen in almost all cases $(96 \%)$, with the dilated glands lacking basal cells (Figure 4B) [16, 17].

The differential diagnosis includes cystic hyperplasia and cystic atrophy of the transition zone [26]. Findings useful in establishing a diagnosis of malignancy within microcystic glands include nuclear atypia, AMACR overexpression, lack of basal cells, and adjacent small acinar adenocarcinoma. Ductal adenocarcinomas of the prostate may also show cystic dilatation of the malignant glands, which can occasionally be seen microscopically and macroscopically $[27,28]$. However, they differ from microcystic acinar adenocarcinomas in that the cysts are typically large (5$10 \mathrm{~mm}$ ) and show intracystic papillae [16, 27]. In contrast, the malignant glands of microcystic acinar adenocarcinoma range from 0.4 to $0.9 \mathrm{~mm}$, and typically have a flat malignant lining layer [17].

The assigned Gleason pattern is 3 for microcystic adenocarcinoma. While this is largely a low-grade adenocarcinoma, up to $36 \%$ of radical prostatectomy cases harbor Gleason pattern 4 elsewhere within the prostate [17], demonstrating that presence of only microcystic adenocarcinoma in a prostate needle biopsy specimen may indicate high-grade pattern 4 in the whole gland that was not sampled at the time of the biopsy. Uncommonly, the microcystic adenocarcinoma glands have been reported to invade into periprostatic adipose tissue [7], leading to a higher $\mathrm{pT}$ tumor classification.

\section{Foamy Gland variant}

Foamy gland adenocarcinoma is typically found as a component of acinar adenocarcinoma (16-22\% of cases) [29] and can be deceptively benign-appearing due to a lack of nuclear atypia [2933]. Clinically, the mean age at diagnosis is 65 years (range 50 78 years) [31] and the preoperative PSA levels resemble those of patients with non-foamy gland carcinomas [32]. Morphologically, 

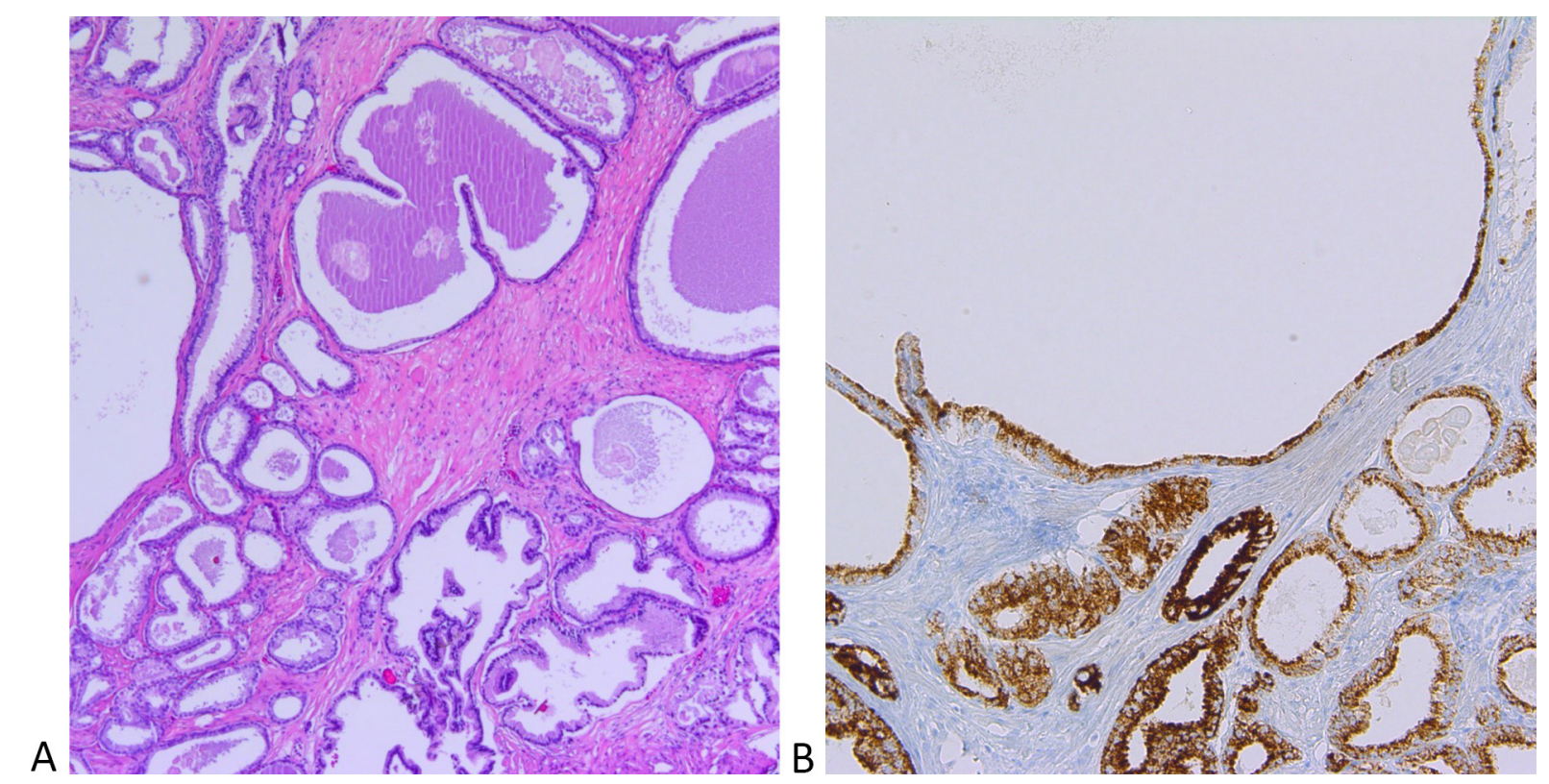

Figure 4. Microcystic variant of acinar adenocarcinoma. A: Cystically dilated glands with rounded profiles and flat luminal linings simulating benign glands with cystic change. Few admixed small malignant glands of the usual acinar adenocarcinoma with abundant cytoplasm and intraluminal mucin (arrow) are seen. (Hematoxylin and eosin stain, 40X magnification); B: AMACR (racemase) and p63 double stain shows intense racemase cytoplasmic staining and lack of $\mathbf{p} 63$ basal cell staining within the glands of the microcystic variant of acinar adenocarcinoma (arrow) as well as acinar carcinoma. (Immunohistochemical stain, 100X magnification).

the foamy gland variant is characterized by abundant foamy/ xanthomatous cytoplasm (Figure 5), often admixed with a nonfoamy gland carcinoma component in $17 \%$ of needle biopsy cases [34], and $13-23 \%$ of radical prostatectomy cases [29]; they are rarely found in pure form. The foamy appearance of the cytoplasm is due to the presence of numerous intracytoplasmic vesicles lacking lipid or neutral mucin [35]. The nuclei are often pyknotic, without nuclear enlargement or prominent nucleoli, however up to $33 \%$ of cases show numerous prominent nucleoli with a Gleason score of 7 (16\%) or above (52\%) [36]. Immunohistochemical studies demonstrate AMACR to be an excellent diagnostic marker for foamy gland carcinoma with AMACR overexpression rates

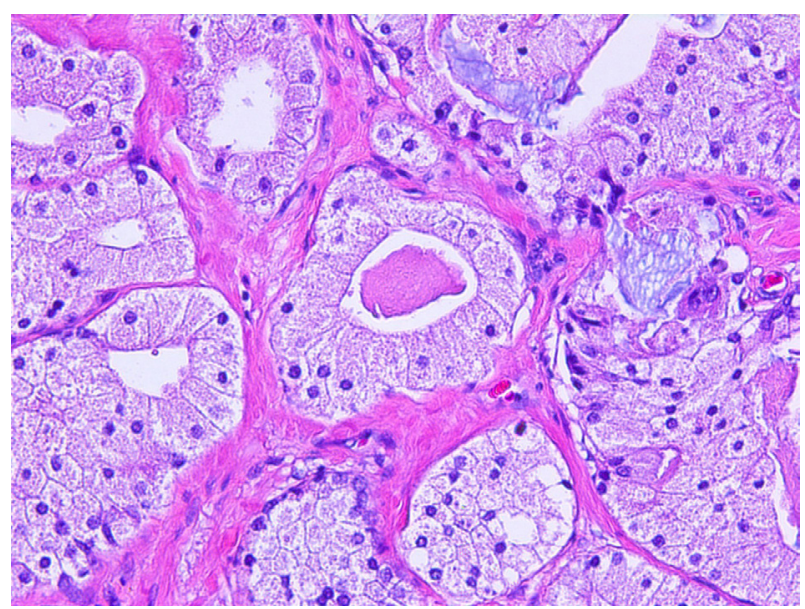

Figure 5. Foamy gland variant of adenocarcinoma seen here characterized by nests of cells with abundant xanthomatous cytoplasm, small pyknotic nuclei, and eosinophilic luminal secretions. (Hematoxylin and eosin stain, 200X magnification). of up to $92 \%$ [29]. Basal cells are absent. TMPRSS2-ERG gene fusion is seen in $29 \%$ of foamy gland adenocarcinomas [37]. ERG protein expression by immunohistochemistry is detected in $42 \%$ of cases [33] but does not provide added diagnostic value beyond detection of AMACR in most cases.

The differential diagnosis includes benign prostatic glands, which can have foamy cytoplasm, as well as foamy macrophages, such as those seen in prostatic xanthomas [34, 35] and granulomatous prostatitis. Positivity for pan-cytokeratin, PSA, PAP, and NKX3.1, and negativity for CD68 can aid in confirmation of foamy gland carcinoma when foamy histiocytes are a consideration. Of note, rare cases of foamy gland high-grade prostatic intraepithelial neoplasia [38], intraductal foamy gland carcinoma [31], and foamy gland change in ductal adenocarcinomas of the prostate [39] have been reported. Androgen deprivation therapy can also induce cytologic changes in prostatic adenocarcinoma cells producing a similar appearance to foamy gland carcinoma with cytoplasmic vacuolization and nuclear pyknosis [40].

The lack of nuclear atypia in foamy glands can create diagnostic difficulties in establishing a malignant diagnosis, particularly in needle biopsy tissue. In contrast to the previously discussed deceptively benign-appearing prostatic adenocarcinomas, high grade foamy gland adenocarcinomas are seen more frequently and observed with Gleason pattern 7 assigned as the most common Gleason score (60\%), followed by Gleason score $6(32 \%)$, Gleason score 8 (3\%), and Gleason score 9-10 (5\%) [29]. Foamy gland carcinoma has a similar prognosis as non-foamy gland adenocarcinoma following prostatectomy [29].

\section{Mucinous (Colloid) variant}

Mucinous adenocarcinoma is defined as a tumor of which at least $25 \%$ has extracellular mucin pools. When mucin is confined within the lumen without spilling into the stroma, it does not qualify as a mucinous carcinoma component. Tumors from other primary 
sites should be excluded with immunohistochemical confirmation of prostate origin. Because of the minimum $25 \%$ mucinous carcinoma volume requirement, this diagnosis can be made reliably only upon sampling of the entire tumor on radical prostatectomy specimens. When evaluating needle biopsy specimens, tumors with this morphology may be more appropriately described as adenocarcinoma with a "mucinous carcinoma component". Due to this requirement, approximately only $0.2 \%$ of prostatic adenocarcinomas are diagnosed as mucinous adenocarcinoma in radical prostatectomy specimens [41-43]. These tumors have no specific epidemiological features.

Mucinous adenocarcinoma is composed of individual glands, fused glands, and cribriform nests floating in large mucin pools and lakes, with the individual tumor cells showing the usual cytologic features of acinar adenocarcinoma. Collagenous micronodules may be present [44] but intracytoplasmic mucin is generally not seen. To determine the grade, the mucin must be ignored, and the usual Gleason criteria must be applied to the underlying architecture. Immunohistochemical studies show positive immunoreactivity for prostate-specific markers and ERG similar to usual acinar adenocarcinoma [45].

Most cases of mucinous adenocarcinoma are assigned Gleason scores of 7 or 8 . Early reports found these to be aggressive tumors [41, 46], however more recently published data suggests that they may have better prognosis than that indicated by the assigned Gleason score [47, 48]. According to a Surveillance, Epidemiology, and End Results Program (SEER) database study, mucinous adenocarcinomas were found to have a similar survival to that of usual adenocarcinomas but superior to those of other adenocarcinoma variants [48].

\section{Signet ring-like cell variant}

Signet ring-like cell variant of prostate carcinoma was so named because the signet ring cell formation in the prostate is usually due to the presence of intracytoplasmic vacuoles, rather than intracytoplasmic mucin. Signet ring cell tumors with intracytoplasmic mucin positive with mucin stains, such as PAS, Alcian blue or mucicarmine stains, are more likely to originate from the bladder or other metastatic sites, such as stomach, colon or rectum. The major differential diagnostic consideration of prostatic signet ring-like cell carcinoma is metastasis or secondary

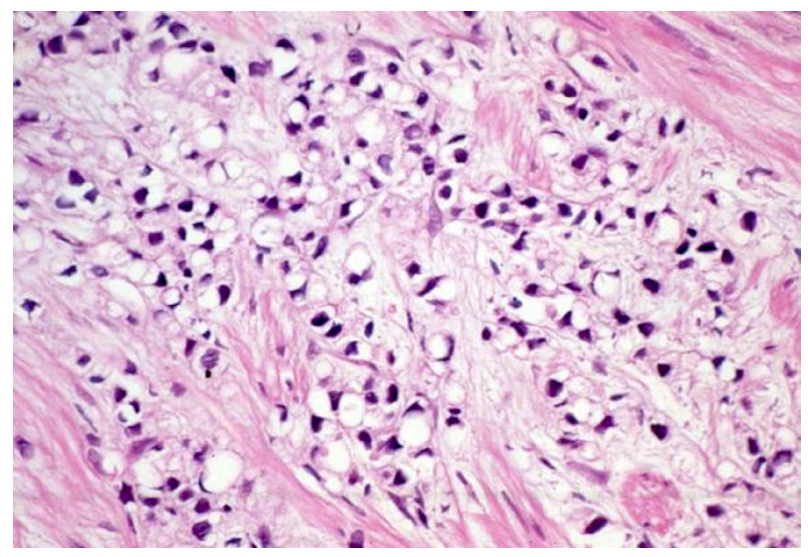

Figure 6. Signet ring-like cell variant. Diffuse infiltration by cords of discohesive round cells with intracytoplasmic vacuoles causing peripheral displacement of nuclei. This carcinoma is usually of high grade (Gleason pattern 5). (Hematoxylin and eosin stain, 200X magnification). involvement of signet ring cell carcinoma from the gastrointestinal or urothelial tract, which are positive for mucin stains and negative for prostate-specific markers. Signet ring-like cell carcinoma requires at least $25 \%$ of tumor cells be composed of signet ring-like cells (Figure 6). Additionally, to make a diagnosis of true signet ring-like cell carcinoma of the prostate, vacuoles must be seen in single isolated tumor cells of Gleason pattern 5. Hormone treated prostate cancers frequently produce signet ring-cell distortion and superficially resemble signet ring-like cell variant of prostate carcinoma. Therefore, hormone treated prostate cancer should be excluded before making a diagnosis of primary signet ring-like cell carcinoma of prostate.

Signet ring-like cell carcinoma of the prostate is rare, with an estimated incidence of 30 cases per 100000 cases of prostate cancer [49]. Clinically, the presentation is similar to conventional acinar prostatic adenocarcinoma [16, 50-53], however this is a highly aggressive tumor, with a mean survival of 29 months [49]. Patients treated with a combination of surgery and hormonal therapy tend to have superior outcomes [49, 52, 54].

\section{Pleomorphic giant cell variant}

An exceptionally rare variant with few cases reported is pleomorphic giant cell variant of adenocarcinoma. This variant contains giant, bizarre, anaplastic cells with pleomorphic nuclei lacking a malignant spindle cell component (Figure 7). Clinically, the mean patient age at diagnosis is 65 years (ranging from 45 to 77 years), with most patients having a history of conventional prostate cancer being treated with hormonal or radiation therapy prior to the diagnosis of pleomorphic giant cell adenocarcinoma being rendered. Morphologically, there is marked pleomorphism involving up to $70 \%$ of the tumor including the possible presence of atypical mitoses. Admixed conventional adenocarcinoma with a Gleason score of 9 or 10 is present in almost all cases of pleomorphic giant cell adenocarcinoma $[55,56]$. Cases are reported to be DNA aneuploid and immunoreactive for cytokeratins using AE1/AE3 and/or CAM 5.2 antibodies. Staining for conventional prostate markers may be negative, with approximately $50 \%$ of cases positive for PSA in the conventional prostate carcinoma component $(1-100 \%)[55,56]$.

The differential diagnosis should include sarcomatoid carcinoma exhibiting occasional pleomorphism and tumors with spindle cells,

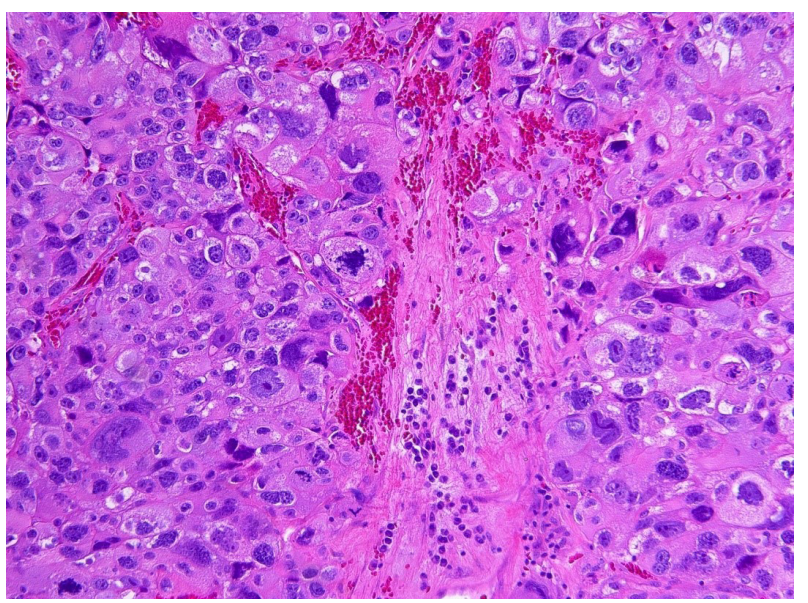

Figure 7. Pleomorphic giant cell variant prostatic adenocarcinoma showing giant, bizarre, anaplastic tumor cells with significant nuclear pleomorphism and atypical mitotic figures. No spindle cell component is seen. (Hematoxylin and eosin stain, 200X magnification). 
osteoclast-type or trophoblastic giant cells. High grade urothelial carcinoma is also an important diagnostic consideration, and urothelial markers such as GATA3 should be performed prior to rendering a diagnosis of pleomorphic giant cell carcinoma of the prostate. These tumors have an extremely aggressive disease course.

\section{Sarcomatoid variant}

Sarcomatoid carcinoma (also known as "carcinosarcoma") is a biphasic malignant neoplasm exhibiting epithelial and sarcomatoid differentiation. Clinically, these tumors present in older men (median age 68 years) $[57,58]$. Approximately half of patients have a history of acinar adenocarcinoma treated with radiation and/or hormonal therapy [58, 59]. Morphologically, some cases display a mixture of a sarcomatoid component and typical adenocarcinoma. Recent molecular studies have shown that both elements are of the same clonal origin [60]. The epithelial component is usually adenocarcinoma with a variable but relatively high Gleason score $[57,58]$ that shows immunoreactivity for cytokeratin, PSA, and PAP. Sarcomatoid components include homologous sarcomatoid components including leiomyosarcoma, liposarcoma, angiosarcoma, and heterologous components with osteosarcoma, chondrosarcoma, rhabdomyosarcoma, and other multiple heterologous lines of differentiation with frequent immunopositivity for various mesenchymal markers $[57,58]$. Sarcomatoid carcinomas tend to have a dismal prognosis, regardless of treatment, showing a 5-year cancer-specific survival rate of $40 \%$ [57].

\section{Small cell carcinoma}

Small cell carcinoma is classified as a separate tumor category in WHO classification, within the neuroendocrine tumors. The discussion of small cell carcinoma in this review is included because small cell carcinoma is often preceded by a diagnosis of acinar adenocarcinoma and rarely presents as a de novo tumor [2]. More than half of small cell carcinomas are associated with a conventional prostatic adenocarcinoma [2, 61, 62]. As in other systems, small cell carcinoma has an aggressive clinical course, however, treatment with chemotherapeutic regimens like those used for pulmonary small cell carcinoma has resulted in a prolonged survival, particularly in patients with only regional lymph node spread [61-66]. These tumors tend to metastasize early to pelvic lymph nodes, lung, and liver, with less commonly reported locations including omentum, vocal cord, temporal bone, axillary lymph node, and peripheral soft tissue [67]. Due to the unique clinicopathologic features of small cell carcinoma, which are typically distinct from those of Gleason pattern 5 acinar adenocarcinoma, these tumors should not be assigned a Gleason score [25].

The histologic and immunohistochemical features are similar to those seen in lung and other extrapulmonary sites including hyperchromatic nuclei and prominent nuclear molding (Figures $\mathbf{8 A}$ and $\mathbf{8 B}$ ), and immunoreactivity for neuroendocrine markers (synaptophysin, chromogranin and CD56). These malignancies can rarely be associated with sarcomatoid and squamous carcinoma components [61]. The cells of some tumors contain dense core neurosecretory granules and show positive immunoreactivity for synaptophysin, chromogranin, and CD56 as well as TTF-1 (50\%) [68], and CD44 (100\%) [67]. CD44 has been found to be negative in most small cell carcinomas of non-prostate origin [68]. A significant subset is frequently negative for prostate tissue markers such as P501S, PSA, and PAP [67].

Small cell carcinoma may be difficult to differentiate from crushed non-small cell carcinoma. If prostatic markers such as

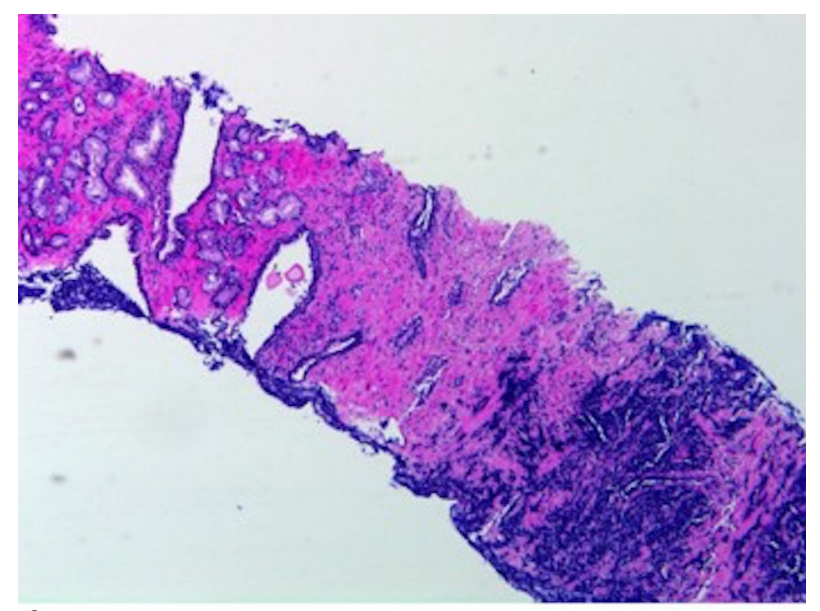

A

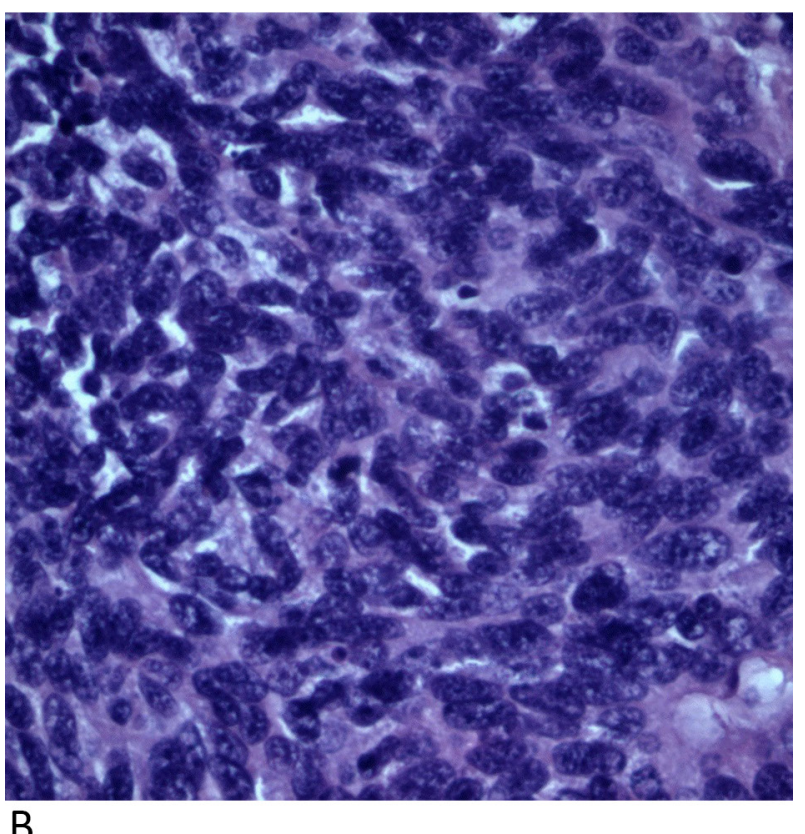

B

Figure 8. Small cell carcinoma of the prostate. A: Small cell carcinoma (right) consisting of tumor cells with hyperchromatic nuclei and nuclear molding with a focus of usual acinar adenocarcinoma (left). (Hematoxylin and eosin stain, 40X magnification); B: Small cell carcinoma showing small round, oval, or spindle cells with hyperchromatic nuclei, inconspicuous nucleoli, and scant cytoplasm with nuclear molding. Few mitotic figures are also seen. (Hematoxylin and eosin stain, 400x magnification).

PSA and PAP are strongly and diffusely positive, a diagnosis of small cell carcinoma should not be made and should instead be interpreted as non-small cell carcinoma. Small cell carcinoma is typically negative or focally, weakly positive for PSA and PAP and positive for neuroendocrine markers.

\section{Conclusion}

It is important to differentiate the histologic variants of prostate acinar adenocarcinoma from benign prostate lesion mimickers and potential metastatic tumors. Important benign mimickers that may be misinterpreted as a variant of acinar adenocarcinoma include lesions such as benign atrophy, benign prostatic hyperplasia, and cystic atrophy. These benign mimickers can be problematic 
when attempting to differentiate them specifically from the atrophic, pseudohyperplastic, and microcystic variants. Benign prostatic glands with foamy features, prostatic xanthomas, and granulomatous prostatitis can cause diagnostic confusion with the foamy gland variant of acinar adenocarcinoma. Although variants such as the mucinous, signet ring-like cell, pleomorphic giant cell, and sarcomatoid variants may not present as diagnostic challenges when evaluating for the presence of malignancy, it is important to rule out involvement by metastatic carcinomas, most commonly of bladder or colonic origin, which will often require the use of immunostains. Additionally, some variants of acinar adenocarcinoma show prognostic differences, further illustrating the importance of accurate recognition. While the atrophic, pseudohyperplastic, microcystic, and foamy gland variants typically show no prognostic difference, the mucinous, signet ring-like cell, pleomorphic giant cell, and sarcomatoid variants are usually higher-grade tumors and are associated with a worse prognosis. Small cell carcinoma of the prostate is not considered a true variant of acinar adenocarcinoma and is not assigned a Gleason score, but is often preceded by a diagnosis of acinar adenocarcinoma and has an aggressive clinical course. A foundational diagnostic awareness of these histologic variants, as well as of their clinicopathologic features, is essential in rendering an accurate diagnosis.

\section{Acknowledgements}

The authors thank Dr. Sasha Pejerrey for her excellent editorial work.

\section{Ethical policy}

This review article was waived from IRB approval.

\section{Author contributions}

The authors contributed equally to this paper. H.S. wrote the paper, reviewed published papers, and prepared photographs. Z.E.Z assisted in writing and proofreading paper and contributed slides for photographs. J.Y.R. is the senior author who provided the idea in preparation of the manuscript, assisted in proofreading of manuscript and approval of photographs.

\section{Competing interests}

The authors declare no competing interests.

\section{Funding}

The authors declare that they have no conflict of interest and received no financial support for this study.

\section{References}

1. Siegel R, Naishadham D, Jemal A: Cancer statistics, 2012. CA Cancer J Clin 2012, 62: 10-29.

2. Ro JY, Amin MB, Ayala AG, Shen SS, Divatia MK: 'Tumors and Tumor-Like Conditions of the male Genital Tract'. In Diagnostic Histopathology of Tumors, 5th edition, Elsevier, Philadelphia, PA. 2020, pp 921-30.

3. Moch H, Cubilla AL, Humphrey PA, Reuter VE, Ulbright TM: 'Tumors of the Prostate' in WHO Classification of Tumours of the Urinary System and Male Genital Organs. Lyon, France: International Agency for Research on Cancer 2016, pp 136.

4. Cina SJ, Epstein JI: Adenocarcinoma of the prostate with atrophic features. Am J Surg Pathol 1997, 21: 287-295.
5. Egan JM, Lopez-Beltran A, Bostwick DG: Prostatic adenocarcinoma with atrophic features: malignancy mimicking a benign process. Am J Surg Pathol 1997, 21: 931-935.

6. Kaleem Z, Swanson PE, Vollmer RT, Humphrey PA: Prostatic adenocarcinoma with atrophic features: a study of 202 consecutive, completely-embedded radical prostatectomy specimens. Am J Clin Pathol 1998, 109: 695-703.

7. Reuter VE: Pathological changes in benign and malignant tissue following androgen deprivation therapy. Urology 1997, 49: 16-22.

8. Wang W, Sun X, Epstein JI: Partial atrophy on needle biopsy cases: a morphologic and immunohistochemical study. Am J Surg Pathol 2008, 32: 851-857.

9. Przbycin CG, Kunju LP, Wu AJ, Shah RB: Partial atrophy in prostate needle biopsies; a detailed analysis of its morphology, immunophenotype, and cellular kinetics. Am J Surg Pathol 2008, 32: 58-64.

10. Amin MB, Tamboli P, Varma M, Srigley JR: Post-atrophic hyperplasia of the prostate gland: a detailed analysis of its morphology in needle biopsy specimens. Am J Surg Pathol 1999, 23: 925-931.

11. Hedrick L, Epstein JI: Use of keratin 903 as an adjunct in the diagnosis of prostate carcinoma. Am J Surg Pathol 1989, 13: 389-96.

12. Adley BP, Yang XJ. Alpha-methylacyl Coenzyme A racemase immunoreactivity in partial atrophy of the prostate. Am J Clin Pathol 2006, 126: 849-855.

13. Brimo F, Epstein JI: Immunohistochemical pitfalls in prostate pathology. Hum Pathol 2012, 43: 313-324.

14. Hameed $\mathrm{O}$, Humphrey PA. Immunohistochemistry in diagnostic surgical pathology of the prostate. Semin Diagn Pathol 2005, 22: 84104.

15. Hameed O, Sublett J, Humphrey PA: Immunohistochemical stains for p63 and alpha-methylacyl-CoA racemase versus a cocktail comprising both, in the diagnosis of prostatic carcinoma: a comparison on the immunohistochemical staining of 430 foci in radical prostatectomy and needle biopsy tissues. Am J Surg Pathol 2005, 29: 579-587.

16. Humphrey PA: Histologic variants of prostatic carcinoma and their significance. Histopathology 2012, 60: 59-74.

17. Yaskiv O, Cao D, Humphrey PA: Microcystic adenocarcinoma of the prostate: a variant of pseudohyperplastic and atrophic patterns. Am J Surg Pathol 2010, 34: 556-561.

18. Humphrey PA: Variants of acinar adenocarcinoma of the prostate mimicking benign conditions. Mod Pathol 2018, 31(S1): S64-70.

19. Wolf AN, Epstein JI. Pseudohyperplastic prostatic adenocarcinoma in needle biopsy and simple prostatectomy. Am J Surg Pathol 2000, 24: 1039-1046.

20. Arista-Nasr J, Barranon-Martinez I, Aquilar-Ayala E, et al: Pseudohyperplastic adenocarcinoma with foamy changes in needle prostate biopsy and prostatectomy. Int J Surg Pathol 2016, 24: 477482.

21. Humphrey PA, Kaleem Z, Swanson PE, Vollmer RT: Pseudohyperplastic prostatic adenocarcinoma. Am J Surg Pathol 1998, 22: 1239-1246.

22. Arista-Nasr J, Martinez-Benitez B, Valdes S, Hernandez M, Bornstein-Quevedo L: Pseudohyperplastic prostatic adenocarcinoma in transurethral resections of the prostate. Pathol Oncol Res 2003, 9: 232-235.

23. Zhou M, Jiang Z, Epstein JI: Expression and diagnostic utility of alpha-methylacyl-CoA-racemase (P504S) in foamy gland and pseudohyperplastic prostate cancer. Am J Surg Pathol 2003, 27: 772778.

24. Egevad L, Epstein JI, Hameed O, Humohrey PA, Samaratunga H: Ductal adenocarcinoma. In: Moch H, Humphrey PA, Ulbright TM (eds). WHO Classification of Tumours of the Urinary System and Male Genital Organs. International Society for Research on Cancer: Lyon, France, 2016, pp 166-167. 
25. Epstein JI, Allsbrook WC Jr, Amin MB et al: The 2005 Internationa Society of Urological Pathology (ISUP) consensus conference on Gleason grading of prostatic carcinoma. Am J Surg Pathol 2005, 29: 1228-1242.

26. Humphrey PA, Young RH. Pseudoneoplastic lesions of the prostate. In: Humphrey PA, Manivel JC, Young RH (eds): Neoplastic Mimics in Genitourinary Pathology, Chapter 4, Fig. 4.39. Demos Medical: New York, NY, USA, 2014, p 113.

27. Paner GP, Lopez-Beltran A, So JS, Antic T, Tsuzuki T, McKenney JK: Spectrum of cystic epithelial tumors of the prostate. Am J Surg Pathol 2016, 40: 886-895.

28. Kojima F, Kuike H, Matsuzaki I et al: Macrocystic ductal adenocarcinoma of prostate: a rare gross appearance of prostate cancer. Ann Diagn Pathol 2017, 27: 7-13.

29. Hudson J, Cao D, Vollmer R, Kibel AS, Grewal S, Humphrey PA: Foamy gland carcinoma of the prostate: incidence, Gleason grade, and early clinical outcome. Hum Pathol 2012, 43: 974-979.

30. Koca SB, Yildiz P, Behzatoglu K: Foamy gland carcinoma in core needle biopsies of the prostate: clinicopathologic and immunohistochemical study of 56 cases. Ann Diagn Pathol 2014, 18: 271-274.

31. Nelson RS, Epstein JI: Prostatic carcinoma with abundant xanthomatous cytoplasm. Foamy gland carcinoma. Am J Surg Pathol 1996, 20: 419-426.

32. Tran TT, Sengupta E, Yang XJ: Prostatic foamy gland carcinoma with aggressive behavior. Histologic, immunohistochemical, and ultrastructural analysis. Am J Surg Pathol 2001, 25: 618-623.

33. Warrick JI, Humphrey PA: Foamy gland carcinoma of the prostate in needle biopsy: incidence, Gleason grade, and comparative alphamethylacyl-CoA racemase versus ERG expression. Am J Surg Pathol 2013, 37: 1709-1714.

34. Chuang AY, Epstein JI: Xanthoma of the prostate: a mimicker of high-grade prostatic adenocarcinoma. Am J Surg Pathol 2007, 31: 1225-1230.

35. Sebo TJ, Bostwick DG, Farrow GM, Eble JN: Prostatic xanthoma: a mimic of prostatic adenocarcinoma. Hum Pathol 1994, 25: 386-389.

36. Zhao J, Epstein JI: High-grade foamy gland prostatic adenocarcinoma on biopsy or transurethral resection: a morphologic study of 55 cases. Am J Surg Pathol 2009, 33: 583-590.

37. Han B, Mehra R, Suleman K, et al: Characterization of ETS gene aberrations in select histologic variants of prostate carcinoma. Mod Pathol 2009, 22: 1176-1185.

38. Berman DM, Yang J, Epstein JI: Foamy gland high-grade prostatic intraepithelial neoplasia. Am J Surg Pathol 2000, 24: 140-144.

39. Lee TK, Miller JS, Epstein JI: Rare histological patterns of prostatic ductal adenocarcinoma. Pathology 2010, 42: 319-324.

40. Srigley JR, Delahunt B, Evans AJ: Therapy-associated effects in the prostate gland. Histopathology 2012, 60: 153-165.

41. Epstein JI, Lieberman PH: Mucinous adenocarcinoma of the prostate gland. Am J Surg Pathol 1985, 9: 299-308.

42. Grignon DJ. Unusual subtypes of prostate cancer. Mod Pathol 2004, 17: 316-327.

43. Ro JY, Grignon DJ, Ayala AG, Fernandez PL, Ordonez NG, Wishnow KI: Mucinous adenocarcinoma of the prostate: histochemical and immunohistochemical studies. Hum Pathol 1990, 21: 593-600.

44. McNeal JE, Alroy J, Villers A, Redwine EA, Freiha FS, Stamey TA Mucinous differentiation in prostatic adenocarcinoma. Hum Pathol 1991, 22: 979-988.

45. Lane Z, Hansel DE, Epstein JI: Immunohistochemical expression of prostatic antigens in adenocarcinoma and villous adenoma of the urinary bladder. Am J Surg Pathol 2008, 32: 1322-1326

46. Lane BR, Magi-Galluzzi C, Reuther AM, Levin HS, Zhou M, Klein EA: Mucinous adenocarcinoma of the prostate does not confer poor prognosis. Urology 2006, 68: 825-830.

47. Osunkoya AO, Nielsen ME, Epstein JI: Prognosis of mucinous adenocarcinoma of the prostate treated by radical prostatectomy: a study of 47 cases. Am J Surg Pathol 2008, 32: 468-472.

48. Marcus DM, Goodman M, Jani AB, Osunkoya AO, Rossi PJ: A Comprehensive review of incidence and survival in patients with rare histological variants of prostate cancer in the United States from 1973 to 2008. Prostate Cancer Prostatic Dis 2012, 15: 283-288.

49. Warner JN, Nakamura LY, Pacelli A, Humphreys MR, Castle EP: Primary signet ring cell carcinoma of the prostate. Mayo Clin Proc 2010, 85: 1130-1136.

50. Saito S, Iwaki H: Mucin-producing carcinoma of the prostate: a review of 88 cases. Urology 1999, 54: 141-144.

51. Guerin D, Hasan N, Keen CE: Signet ring cell differentiation in adenocarcinoma of the prostate: a study of five cases. Histopathology 1993, 22: 367-371.

52. Gumas E, Yilmaz B, Miroglu C: Prostate mucinous adenocarcinoma with signet ring cell. Into J Urol 2003, 10: 239-241.

53. Ro JY, El-Naggar A, Ayala AG, Mody DR, Ordonez NG: Signetring-cell carcinoma of the prostate. Electron microscopic and immunohistochemical studies of eight cases. Am J Surg Pathol 1988, 12: 453-460.

54. Derouiche A, Ouni A, Kourda N, Belhadj K, Ben Jilani S, Chebil M: A new case of signet ring cell carcinoma of the prostate. Clin Genitourin Cancer 2007, 5: 455-456.

55. Lopez-Boltran A, Eble JN, Bostwick DG: Pleomorphic giant cell carcinoma of the prostate. Arch Pathol Lab Med. 2005; 129: 683-685.

56. Parwani AV, Herawi M, Epstein JI. Pleomorphic giant cell adenocarcinoma of the prostate: report of 6 cases. Am J Surg Pathol 2006, 30: 1 254-259.

57. Fukawa T, Numata K, Yamanaka M, el al: Prostatic carcinosarcoma: a case report and review of literature. Int J Urol 2003, 10: 108-113.

58. Hansel DE, Epstein JI. Sarcomatoid carcinoma of the prostate: a study of 42 cases. Am J Surg Pathol 2006, 30: 6-21.

59. Dundore PA, Cheville JC, Nascimento AG, Farrow GM, Bostwick DG: Carcinosarcoma of the prostate. Report of 21 cases. Cancer 1995, 76: 1035-1042.

60. Ray ME, Wojno KJ, Goldstein NS, Olson KB, Shah RB, Cooney KA: Clonality of sarcomatous and carcinomatous elements in sarcomatoid carcinoma of the prostate. Urology 2006, 67: 423.e5423.e8.

61. Tetu B, Ro J Y, Ayala A G, Johnson DE, Logothetis CJ, Ordonez NG: Small cell carcinoma of the prostate. Part I. A clinicopathologic study of 20 cases. Cancer 1987, 59: 1803-1809.

62. Ro J Y, Tetu B, Ayala A G, Ordonez NG: Small cell carcinoma of the prostate. II. Immunohistochemical and electron microscopic study of 18 cases. Cancer 1987, 59: 977-982.

63. Amato R J, Logothetis C J, Hallinan R, Ro J Y, Sella A, Dexeus F $\mathrm{H}$ : Chemotherapy for small cell carcinoma of prostatic origin. J Urol 1992, 147: 935-937.

64. Oesterling J E, Hauzeur C G, Farrow G M: Small cell anaplastic carcinoma of the prostate: a clinical, pathologic and immunohistological study of 27 patients. J Urol 1992, 147: 804-807.

65. Hindson D A, Knight L L, Ocker J M: Small cell carcinoma of prostate: transient complete remission with chemotherapy. Urology 1985, 26: 182-184.

66. Randolph TL, Amin MB, Ro JY, Ayala AG et al: Histologic variants of adenocarcinoma and other carcinomas of prostate: pathologic criteria and clinical significance. Mod Pathol. 1997, 10: 612-629.

67. Simon R A, di Sant'Agnese P A, Huang L S, Xu H, Yao J L, Yang, Q et al: CD44 expression is a feature of prostatic small cell carcinoma and distinguishes it from its mimickers. Hum Pathol 2009, 40: 252258.

68. Wang W, Epstein J I: Small cell carcinoma of the prostate: a morphologic and immunohistochemical study of 95 cases. Am J Surg Pathol 2008, 32: 65-71. 